\title{
LVII. On the mathematical laws of electrical influence
}

\section{R. Murphy Esq. M.A.}

To cite this article: R. Murphy Esq. M.A. (1833) LVII. On the mathematical laws of electrical influence, Philosophical Magazine Series 3, 2:11, 350-351, DOI: $10.1080 / 14786443308648055$

To link to this article: http://dx.doi.org/10.1080/14786443308648055

曲 Published online: 01 Jun 2009.

Submit your article to this journal \lceil

Џ Article views: 3

Q View related articles $\sqsubset$ 
Set, No.6.-With a maintaining power of 5 pounds weight. $\begin{array}{lcl}\text { Experiments. } & \text { Loss in } & \text { Extent of } \\ & 24 \text { Hours. } & \text { Vibration. }\end{array}$

With hair............ $-2^{\mathrm{m}} 7 \cdot 5^{\mathrm{s}} \quad \ldots \ldots \ldots \ldots \ldots . .1 \cdot 8^{\circ}$

Ditto...............

Without hair.......... $-2 \quad 6 \cdot 0 \quad \ldots \ldots \ldots \ldots . . .20$

The loss of 1 second in the rate of the pendulum arising from the increase of friction in consequence of its slight contact with the hair, may be explained as follows: The impulse given to the pendulum was all during its ascent; this caused all the friction that would affect the time to be in its descent. Since the friction in its ascent would fall into the impulse, it would occasion a diminution of its power only, but have no effect on the time of the ascent; it would, however, have its full effect on that of the descent, and produce the loss of 1 second, as shown by experiment.

[To be continued.]

LVII. On the Mathematical Laros of Electrical Infuence. By R. Murphy, Esq. M.A. Fellow of Caius College, Cambridge*.

FEW exact results, in the mathematical sense of the word, have been obtained with respect to the distribution of electricity when any number of electrized bodies mutually influence each other. M. Poisson has established a very simple principle for reducing such problems to analysis, and another may be announced by assuming the influences to be consecutive: thus if two spheres $A$ and $B$ mutually influence each other, we may suppose, first, that $\mathbf{A}$ alone influences $B$; secondly, that the disturbance thus produced in $B$ influences $A$, and so on: by this means we may arrive at the final distribution of electricity on the surfaces of $A$ and B.-The following exact results of influencing bodies may be noticed.

If any number of concentric shells, the thickness of any one of which is uniform, are charged with electricity, the quantity of electricity developed on the outer surface of any shell will be the sum of the charges of all the interior shells, including the individual shell itself; and on its inner surface, the same sum excluding that shell.

If a very remote body influence an electrized sphere, the section made by a plane through its centre perpendicular to the direction of the disturbing force, will contain those points on the surface which are not influenced, and the influence at

* Communicated by the Author. 
any other point is as the sine of the angle which the radius drawn to that point makes with the above plane.

If an electrized point influence an electrized sphere, the influence at any point is as a constant quantity minus another quantity which varies inversely as the cube of the distance from the influencing point.

April 10, 1833.

R. Murphy.

LVIII. On the Law of the Diffusion of Gases. By Tномas Graham, Esq. M.A. F.R.S. Ed., Professor of Chemistry in the Andersonian University, Glasgow.

[Concluded from p. 276.]

\section{Carbonic Oxide.}

SPECIFIC gravity, 0.9722 , \&c. as in the case of nitrogen. $D$ Gas prepared by the action of sulphuric acid on crystallized oxalic acid, well washed with caustic ley.

On 803 measures carbonic oxide and vapour, a contraction of 11 measures in fifty hours, 12 measures in eighty-nine hours, 12 measures in ninety-seven hours; or 803 became 791. The diffusion was slower than usual, from the plug having been partially wetted in filling the instrument with gas.

$$
\frac{815}{803}=1.0149=\text { diffusion-volume of carbonic oxide, by ex- }
$$
periment.

theory.

$1 \cdot 0140=$ diffusion-volume of carbonic oxide, by

In the case of the last three gases, when the experiment was performed over water in a diffusion-tube, with free exposure to the dry atmosphere, instead of any contraction ensuing, a positive expansion generally occurred, which was to be attributed to the return air, which was comparatively dry, being expanded after entering the receiver.

14. Carburetted Hydrogen of Marshes. - Specific gravity, 0.555. Diffusion-volume, 1.34.14.

In an experiment with this gas, deducting a small quantity of air which it contained, 252 measures were replaced by 187 air.

$$
\begin{aligned}
\frac{252}{187}=1.344 & =\text { diffusion-volume, by experiment. } \\
1.341 & =\text { diffusion-volume, by theory. }
\end{aligned}
$$

These are all the permanent gases which could conveniently be submitted to diffusion. Vapours cannot be rigidly examined, as they are all condensible in the pores of the stucco. The following Table exhibits a summary of the results: 